The Turkish Online Journal of Design, Art and Communication - TOJDAC

ISSN: 2146-5193, September 2018 Special Edition, p.1037-1043

\title{
ELECTRONIC MUSICAL INSTRUMENTS: FEATURES OF CHILDREN'S CREATIVE DEVELOPMENT IN THE LEARNING PROCESS
}

\author{
Igor M. KRASILNIKOV \\ Institute of Art Education and Cultural Studies of the Russian Academy of Education, Russia \\ Oleg D. NIKITIN \\ Institute of Art Education and Cultural Studies of the Russian Academy of Education, Russia
}

\begin{abstract}
The involvement of children in music creation with electronic instruments has been actively developing in Russia in the last twenty years. The goal of the study is to comprehend the accumulated experience from the psychological and pedagogical positions and to determine the features of the creative development of children involved in this activity. For this purpose, the analysis of the factors influencing the creative development of children due to the specifics of the electronic digital tools has been undertaken. Particular attention was paid to the electroacoustic, electronic and digital nature of these tools. An experimental study of the problem is also considered, based on the survey of leading teachers of electronic instruments from different regions of Russia. The conclusions of the article allow us to outline the prospects for the development of electronic musical creativity as a new type of educational and artistic activity in general, additional and professional education.
\end{abstract}

Keywords: Children, Music Education, Creative Development, Electronic Instruments.

\section{INTRODUCTION}

\section{Problem statement}

In the additional education of children, the electronic musical creativity has been actively developing as a new kind of educational and artistic activity in Russia in the last twenty years. In Russia, approximately 2000 children's music schools, art schools, children's art houses have opened classes of electronic keyboard and computer music studios. There are numerous festivals and competitions for children and youth performing in the electronic music genre in dozens of cities.

At the same time, the new direction of educational activity does not always meet the understanding of teachers, educational institutions' management, methodologists and even scientific and pedagogical workers. The new digital toolkit for many of them is associated with pop or rock music, mostly built on primitive stamps. Others, on the contrary, define electronic music as an experimental, in fact, an exclusive area of artistic activity. Still, some believe that the electronic tools are deliberately flawed because they are based on the "lifeless" sound, separated from the muscular efforts of the musician, while the fashion explains the interest of students and fellow teachers and its rapid spread in the educational practice.

Apparently, such criticism, attributing genre, stylistic or expressive limitations to the new instrumentation and, correspondingly, a decrease in the quality of musical instruction, is intended to justify the inexpediency of this instruction.

The enthusiasts, who introduce the information and communication technologies (ICT) in music education, encounter such problems in many other countries. Thus, in Australia, the state curriculum on music distinguish music and information technologies (Crawford \& Southcott, 2017). Most UK school teachers remain conservative in their approaches to teaching composition, despite the efficiency and availability of digital technologies in the educational process (Wise, 2016). Spanish researchers complain: even though ICT rapidly comes in all professions and leisure, this process is slower in the educational sector (Chao-Fernandez, Roman-Garcia, Chao-Fernandez, 2017). 
Many educators, methodologists, and scientists around the world are looking for new ways of optimising music education corresponding to ITC capabilities (Addessi, Anelli, Beghi, 2017; Horita, 2014; Lopez-Garcia, 2016; Serrano, 2017; Silva \& Martins).

Their work, as a rule, is accompanied by negative comments from teachers, focused on traditional methods of music training. However, how fair are their critical arguments? Why are training tasks more complicated? How does the musical development of students at an electronic keyboard and a computer studio class reveal? What are the psychological and pedagogical characteristics of the children creative development when learning to play electronic musical instruments?

The answers to these questions are considered to be the key features in determining the significance and prospects of this new area of educational and artistic activity.

\section{Specifics of teaching to play electronic musical instruments}

According to the psychological provisions on the unity of consciousness and activity (Rubinshteyn, 1946; Vygotsky, 1997), the activity essence of abilities (Leontiev, 1977; Teplov, 1961) new psychological formations, including the characteristics of children's talent development, are determined by the specific nature of the activity that generated them.

The electronic tools have a digital nature. Thus, the electronic keyboard, in its essence is a specialized music computer. The digital nature designates the characteristics of creative activity to a large extent.

\section{How are these features expressed?}

First of all, the sound of both digital instruments and many "relatives" - electrified and based of analog synthesis - is based on electroacoustics, which leads to the expansion of the expressive possibilities of music. The dynamic range increases significantly in the new electro-acoustic conditions. It gives an opportunity to adjust the spatial organization of sound. Loudspeakers create an artificial acoustic space in which voices can move along the front and depth of the sound picture, and the picture itself can increase or decrease in size.

The sound volumes are characterized by variability, diversity, while the actual acoustics within the listening does not play a fundamental role. The appearance of electroacoustics released the music outside the concert halls, opera houses - it appeared literally in every house. With the help of electroacoustic equipment, any outdoor venue, including a large sports stadium, can serve as a concert stage. Thanks to electroacoustics, music has gained an unprecedentedly wide audience, and it is incorrect to speak about elitism, as its originally assigned nature on this technological basis.

Secondly, digital tools are a type of electronic toolkit. Its nature is connected with the possibility of the work with sound at a microstructure level, which opens new horizons in working with the timbre palette. The sound material of electronics allows making artistic discoveries, and primitive, clichéd musical creativity on its basis, bordering within the frame of mass culture (another widespread prejudice) is not connected with its nature, for sure.

Due to the huge variety of sound material in electronic music, the color of each musical piece is especially valuable. To achieve outstanding results for the composer it is not sufficient enough to create a notation text as a musical project. In addition, a composer must translate it into a sound that differs in its original color, intonation, and spatial fullness. That is, his task is to create virtual voices, develop a performing and a sound text interpretation. Integration of various types of musical activity extends its space. Thus, the conditions for the harmonious development of musical abilities become more favorable as compared to the traditional activities - composer, performer and sound engineer specialization. This integration is the foundation for constructing the electronic music teaching, which includes significant components of the disciplines mentioned, as well as experience in creating original voices.

Thirdly, a modern electronic instrument is based on chip-integrated circuits, which, in comparison with analog predecessors, determines its wide functional potential, ease of operation, small size and low price. Due to this technical innovation, the electronic musical creativity has turned from an elite 
activity into a public one - today it belongs not only to professionals but also to amateurs, including children.

The digital filling predetermined the dialogue of the electronic tool user and the programmer, which is represented in this interaction by a computer program. Computer interactivity in electronic music creativity opens opportunities, on the one hand, to facilitate the process of sound synthesis and regulation of many composers, performance, sound parameters, and on the other hand - to build different models of the user-programmer interaction. The construction of these models depends on different contributions of the participants involved in music-computer communication and creation of the product - the less the user's contribution, the more the programmer's contribution, and vice versa. Thus, there is an inverse relationship between their contribution proportion in creating the composition.

For example, some computer programs assume that the user relies not only on the musical sounds created by the programmer, but also on the workpieces of the texture. The user composes a mosaic of them, similar to a child's construction kit. It is much easier. So, without the knowledge of musical notation, a person can create long musical compositions that sounds harmonious. Though these compositions are unlikely to have originality and stylistic diversity since the product in such programs is determined by the peculiarities of the sound of pre-created musical pieces.

In another case the user can take on a larger amount of work and rely on the ready-made timbres of the melody and accompanying patterns of auto-accompaniment. The music product, in this case, becomes more original, although the user's task becomes more complicated. The user should not only master a musical notation, but also have experience in working with expressive means related to a composer's (harmony, texture, instrumentation), performer's (tempo, agogics, dynamics, articulation), and sound engineer's activity (time, frequency, amplitude and spatial correction of sound).

In the third case, the user completely works on the construction of the musical texture, and the programmer only creates timbres. The product's originality is growing, but, on the other hand, his competencies in composition, performance and sound engineering must be on a significant level.

And, finally, the creation of a composition based on the user sounds can be recognized as the most complex and at the same time the most promising for artistic discoveries option of electronic musical creation.

Thus, first of all, this activity is not pre-determined for working with preset sounds. On the contrary, its highest achievements are determined by the originality of the color obtained with the help of the original sound material created by the author. Today, even a cheap electronic keyboard has the sound editing function and the ability to flexibly control the sound and is equipped with a dynamic keyboard, foot pedals, and other electronic means. Digital technologies are rapidly improving, and it can be assumed that soon the ability to respond to the user's muscular efforts on household electronic instruments will be close to the level of traditional mechanical tools. However, even without addressing to a variety of performing and timbre creating functions, electronic music will still successfully develop the artistic talents of students, since in addition to performing and sound synthesis they solve problems related to a composer and sound creativity in the activity.

It should also be noted that musical activity based on modern electronic instruments is very diverse. Here, both the novice amateur and the professional can find a suitable niche. Besides, this interactive environment allows the amateur, despite his musical abilities, to achieve full-fledged musical sounding, and the professional - to achieve originality and freshness.

The technique of introduction to musical creativity based on digital instruments can be constructed considering the mentioned user - programmer interaction types in the interactive environment. At first, the tasks of the student in the electronic instrument class can be limited to the selection of patterns of auto accompaniment, instrumentation, and harmonization of the melody, then include the construction of the texture in its full form with the help of ready-made timbres, and then - their self-created varieties. 
Thus, the increasing role of the electronic instrument user connected with the moving to higher levels of complex tasks within this methodological approach causes the complication of the sound material for operation. In this regard, all the components of electronic musical creativity - composing, performing, sound and sound production and the creation of new timbres - are complicated, which determines both the musical talent developing and the variety of its components. The brightness, the fullness of the sound of musical activity products created in the class of electronic instruments, affordable even for beginners, the prospect of creative development, open for amateurs and professionals, determines the interest in electronic musical creativity.

As we can see, the nature of electronic instruments determines the features of the musical creativity and the development of many valuable creative qualities of the individual. How do these advantages of electronic musical creativity reveal themselves in actual pedagogical practice?

\section{METHODS}

A survey by questionnaire was conducted, as a part of the research, aimed at determining the specifics of using the capabilities of modern electronic tools in the process of teaching children and identifying the factors that contribute to the development of their creative abilities. The questionnaire consisted of twelve questions and was anonymous. The survey involved leading teachers of music schools in Russia on electronic musical instruments. The total number of participants was 30 .

\section{RESULTS}

Based on the survey, the following results were obtained:

More than $95 \%$ of teachers believe that classes on modern electronic musical instruments contribute to the development of the creative potential of students. Most teachers mention the following positive features in their development:

- the use of synthesizers and computers in music training contributes to a qualitatively new level of children's performing and composing skills;

- students learn to play the synthesizer with pleasure, do computer arrangements, compose music, create sound recordings of songs;

- the electronic toolkit promotes the development of artistic and creative potential, and causes interest in musical art;

- training in the class of electronic musical instruments gives graduates a real opportunity not only to discover their creative potential but also to get a real start for future professional activity.

According to the results of the survey, more than $60 \%$ of teachers noticed that classes of electronic instruments have a positive impact on the process of harmonizing the personality of a student. They note that this activity increased a self-esteem of almost all children, formed a desire to demonstrate their skills to peers in school, and evolved creative initiatives.

Most teachers (80\%) noted the growing interest of children in creative activities with modern digital instruments:

- electronic music today is becoming increasingly popular in children's art education. It is proved by the growing number of competitions and festivals for young performers, attracting more and more participants every year;

- children's music and art schools have good potential for introducing the younger generation to electronic music creation;

- the interest in this activity in children is growing. Digital technologies are an effective tool for developing the musical and creative abilities of children. 
The interest of children in electronic music-making, in the first place, is connected with the diversity of possibilities for self-expression. More than $80 \%$ of teachers noted the following facts:

- digital technology is a priority in the modern world. Modern children feel its influence from an early age. Computer enthusiasm is observed from preschool and junior school age, but such early computerization is not always associated with the development of creativity and sometimes negatively affects the development of thinking and spirituality;

- considering the electronic keyboard as a music computer, a child shows more interest in this instrument than in the mechanical instruments;

- there are much more children wishing to take a class of electronic musical instruments than other classes;

- electronic instrument education provides wide opportunities for revealing the creative potential of children, developing their talent and forming a mental world.

Electronic music making in childhood, in the opinion of $30 \%$ of teachers, stimulates musical and creative expression in subsequent age periods. According to their observations, the desire of pupils to play the electronic instruments remains after finishing art school, mainly as a hobby, but some wish to professionally continue their music education in secondary and higher vocational schools.

More than half of the surveyed teachers note the correlation between a child's desire to engage in ensemble and electronic instruments training. Here is an example - the statement made by a teacher with a vast experience of work at a music school: "On the basis of my experience I can note that long ago, when I was teaching the piano (for 30 years), I did not observe the desire to play music from students who graduated from music school, which I've started noticing since I began to teach the electronic keyboard. Some of my graduates, being higher school students, not only play music but also form music bands or play in a band and perform with concert programs in various venues of the city, which was not observed among students who graduated from the piano course".

Some teachers selectively asked their students the questions from the questionnaire. The answers of the students, in our opinion, add and enrich the picture of the research: "Recently I conducted a survey among my students. I asked them a question from your questionnaire. The results of the survey: 1 . Katya Koroleva, 16: "The synthesizer training helped me to reveal and form the possibilities of my composer creativity. The synthesizer is the tool of my future". After finishing the school, Katya is going to continue her music education in composition. Today, she is the author of several songs (she became a 1-degree laureate of the International Competition "Music and Electronics" in 2016). 2. Alevtina Sapozhnikova, 13: "For me, learning how to play synthesizer is an opportunity to create works different from the works for mechanical instruments. It helps to develop a sight in a new perspective, to hear and see ordinary phenomena through the prism of sounds. The teaching capabilities of synthesizer contribute to all this. In future, I will definitely continue playing the synthesizer. It will be my hobby". 3. Igor Golyashin, 13: "For me, learning how to play the synthesizer is an opportunity to engage in creativity, especially arranging, creating your own styles. I am very interested in the technical capabilities of a synthesizer. And in future, I see it as an instrument on which there are no keys, and sounds emerge from the power of thought, from a distance. In future, I will definitely continue playing music, and do arrangements as a hobby".

Most teachers encourage their students to edit musical timbres. Their students believe that editing the musical timbre is one of the most interesting and creative synthesizer lessons.

\section{DISCUSSION}

Currently, the desirability of teaching how to play electronic instruments is under discussion. Taking into account the results of the conducted research, we can note on a number of factors of this training that positively affect the creative development of students. 
These instruments have a large set of musical timbres. By analyzing and listening to these timbres, modern children learn to distinguish the nuances, it aggravates hearing, improves memory and forms the idea of the integral sound image.

The work on editing musical timbres helps to improve the concentration of attention and allows students to experience the emotional color of each sound more subtly, which can contribute to a subtler differentiation of the child's emotions.

The work on creating a panorama and work with sound effects (reverb, echo, wah, distortion, etc.) develop spatial perception and thinking, and allow selecting a significant auditory figure from the general background, play with it and give it some meaning in the musical composition. These actions contribute to the formation and development of a child's ability to analyze and synthesize and allow us to consider the music piece cohesively.

The work of creating a musical piece using the function of imposing different instruments and applying effects of processing and synthesis of sound develops memory, logical thinking the ability to process information in integral audio blocks.

\section{CONCLUSION}

Learning how to play electronic instruments stimulates the creative development of children in connection with their involvement in solving problems of choosing the repertoire, arranging and performing musical compositions.

Working with the microstructure of sound allows making artistic discoveries and contribute to the development of students' creativity. This work significantly expands the possibilities of expressing various emotional, imaginative and semantic nuances of a musical work, which contributes to their emotional and intellectual development.

Work with sound space and effects develops the skills of spatial perception and thinking and contributes to the actualization of the processes of detailing information, analysis, and synthesis.

Integration of performing, composer, sound, and timbre creation allows overcoming the one-sided performance of music education and determine the harmonious development of musical abilities of students.

Aiming at creating a holistic musical product, that includes many system-linked elements, develops students' ability of dialectical thinking.

The possibility of working with the computer-aided functions of digital tools removes insecurity and fear from children and turn learning into an exciting game.

When playing the electronic instruments, tasks of any complexity can be set. It gives the activity a perspective of professional improvement.

The opportunity to express themselves in diverse interactive activities - from those requiring minimal technical skills to those requiring professional music training - greatly widen the contingent of students. And, hence, electronic musical creativity as a new type of educational and artistic activity has the broadest development prospects in general, additional and professional education.

\section{ACKNOLEDGMENT}

The results of the research were obtained within the framework of the state task of the Ministry of Education and Science of Russia for the project "Development of artistic talent of children and adolescents by means of information and communication technologies", 27.8719.2017/БЧ (Number for publications: 27.8719.2017 / 8.9). The authors are grateful to the directory of the Institute of Art Education and Cultural Studies of the Russian Academy of Education for scientific and material support of the research, to the teachers of electronic musical instruments of general and additional educational institutions of Moscow and Moscow region, St. Petersburg, Vladivostok, Ivanovo, 
Izhevsk, Kaliningrad, Krasnoyarsk, Novosibirsk, Perm, Syktyvkar, Chelyabinsk, Yaroslavl, who participated in the experimental work and questioning

\section{REFERENCES}

Addessi, A.R., Anelli, F., Benghi, D. (2017). Child-Computer Interaction at the Beginner Stage of Music Learning: Effects of Reflexive Interaction on Children's Musical Improvisation. Frontiers in Psychology. https://doi.org/10.3389/fpsyg.2017.00065

Chao-Fernandez, R., Roman-Garcia, S., Chao-Fernandez, A. (2017). Analysis of the use of ICT through music interactive games as an educational strategy. 7th International Conference on Intercultural Education - Education, Health and ICT - From a Transcultural Perspective: Almeria, Spain. Procedia Social and Behavioral Sciences, 237, 576-580.

Crawford, R., Southcott, J. (2017). Curriculum stasis: the disconnect between music and technology in the Australian curriculum. Technology pedagogy and education, 26(3), 347-366.

Horita, T. (2014). Trend and problems of informatization at school education. Japanese Journal of Music Education Practice, 11(2), 6-13.

Leontiev, A.N. (1977). Deyatel'nost'. Soznanie. Lichnost' [Activity. Consciousness. Personality]. Moscow, 304.

Lopez-Garcia, N.J. (2016). Evaluation and ITC in primary education: using plickers to evaluate musical skills. Ensayos-revista de la facultad de educacion de Albacete, 31(2), 81-90.

Rubinshteyn, S. (1946). Osnovy obshchey psikhologii [Fundamentals of General Psychology]. Moscow: MP RSFSR, 720.

Serrano, R.M. (2017). Technology and compulsory music education in Spain: references for the implementation of good practices. Revista electronica complutense de investigacion en educacion musical-reciem, 14, 153-169.

Silva, N., Martins, C. (2016). An ICT-based approach to improve the pedagogy states of musical arts education. 10th International Technology, Education and Development Conference: Valencia, Spain. Book Series: INTED, 4582-4587.

Teplov, B.M. (1961). Psikhologiya muzykal'nykh sposobnostey [Psychology of musical abilities]. Collection: Problems of individual differences. Moscow: APN RSFSR, 384.

Vygotsky, L.S. (1997). Lektsii po psikhologii [Lectures on phsycology]. Soyuz Saint Petersburg, 142.

Wise, S. (2016). Secondary school teachers' approaches to teaching composition using digital technology. British journal of music education, 33(3), 283-295. 